development of cocaine-exposed and control infants from birth through 15 months: poor and poorer performance. Pediatrics Nov 1996;98:938-943). The combination of cocaine exposure and poor nutrition is a cumulative risk factor for impaired infantile motor performance in minority subjects and potentially detrimental to later neurocognitive development.

\title{
ASYMPTOMATIC HEAVY LEAD EXPOSURE
}

Three asymptomatic children, ages 34, 23, and 26 months, with blood lead levels $>100 \mathrm{mcg} / \mathrm{dL}$ on routine screening are reported from the Kennedy Krieger Institute and Department of Pediatrics, Johns Hopkins, Baltimore, MD. All suffered from pica and one was described as "hyper." Screening appears to be essential in at risk children if lead poisoning is to be detected and eradicated. (Davoli CT, Serwint JR, Chisolm JJ Jr. Asymptomatic children with venous lead levels $>100 \mathrm{mcg} / \mathrm{dL}$. Pediatrics Nov 1996;98:965-968). (Reprints: Cecilia T Davoli MD, Kennedy Krieger Institute, 707 North Broadway, Baltimore, MD 21205).

COMMENT. It is unfortunate that children must be used as "lead detectors" before lead violations in homes and schools are corrected and lead abatement instituted. Critics of routine screening at 6 months to 6 years must be impressed by this report and conclude that in certain populations, screening is the only way to prevent childhood morbidity and mortality from lead exposure.

\section{INFECTIOUS DISORDERS}

\section{NEUROCYSTICERCOSIS WITHOUT RISK FACTORS}

Two unusual cases of cysticercosis in children, ages 6 and 3 years, without risk factors or infected contacts, and five additional cases in children $<2$ years, are reported from Loyola University Chicago Stritch School of Medicine, Maywood, IL; University of Illinois at Chicago Medical Center; Children's Memorial Hospital, Chicago; and Centers for Disease Control and Prevention, Atlanta, GA. The source of infection was not identified in cases 1 and 2, and pork was never or only occasionally consumed. Both children were born and lived in Chicago. One had travelled to Ireland twice, where cysticercosis is not endemic. Cases 3 to 7 were born in the US, but had parents and other relatives from Latin America. Five patients had focal seizures and two had generalized seizures, as the presenting symptoms in 6 cases. One child presented with an inflamed, cystic, subcutaneous swelling on his back. An initial CT was negative, but a ring-enhancing lesion in the temporal lobe was found after seizures developed and before antiparasitic therapy was instituted. All other cases had positive CTs on admission. After treatment with dexamethasone for 3 days and praziquantel for 15 days, seizures did not recur. (Stamos JK, Rowley AH, Hahn YS, Chadwick EG, Schantz PM, Wilson M. Neurocysticercosis: report of unusual pediatric cases. Pediatrics Nov 1996;98:974-977). (Respond: Julie Kim Stamos MD, Section of Pediatric Infectious Diseases, Loyola University Medical Center, Department of Pediatrics, 2160 South First Ave, ET Bldg, 8th Floor, Maywood, IL 60153).

COMMENT. Neurocysticercosis in the US is rare, especially in children, but an increased incidence in the last decade is reported, even in patients who have never travelled to endemic areas. Taenia solium eggs may survive under 